\title{
Human Piebald Trait Resulting from a Dominant Negative Mutant Allele of the c-kit Membrane Receptor Gene
}

\author{
Roger A. Fleischman \\ Simmons Cancer Center, Department of Medicine, University of Texas \\ Southwestern Medical Center, Dallas, Texas 75235
}

\begin{abstract}
Human piebald trait is an autosomal dominant defect in melanocyte development characterized by patches of hypopigmented skin and hair. Although the molecular basis of piebaldism has been unclear, a phenotypically similar "dominant spotting" of mice is caused by mutations in the murine c-kit protooncogene. In this regard, one piebald case with a point mutation and another with a deletion of c-kit have been reported, although a polymorphism or the involvement of a closely linked gene could not be excluded. To confirm the hypothesis that piebaldism results from mutations in the human gene, c-kit exons were amplified by polymerase chain reaction from the DNA of 10 affected subjects and screened for nucleotide changes by single-stranded conformation polymorphism analysis. In one subject with a variant single-stranded conformation polymorphism pattern for the first exon encoding the kinase domain, DNA sequencing demonstrated a missense mutation (Glu ${ }^{583} \rightarrow$ Lys). This mutation is identical to the mouse $W^{37}$ mutation which abolishes autophosphorylation of the protein product and causes more extensive depigmentation than "null" mutations. In accord with this "dominant negative" effect, the identical mutation in this human kindred is associated with unusually extensive depigmentation. Thus, the finding of a piebald subject with a mutation that impairs receptor activity strongly implicates the c-kit gene in the molecular pathogenesis of this human developmental defect. (J. Clin. Invest. 1992. 89:1713-1717.) Key words: pigmentation disorders • melanocytes
\end{abstract}

\section{Introduction}

Human piebald trait is characterized by autosomal dominant inheritance, a white hair forelock, stable areas of hypopigmentation or "leukoderma" on the anterior trunk and extremities, and the absence of extracutaneous manifestations (1). In contrast to other albino syndromes, the affected areas in piebaldism are devoid of melanocytes, presumably resulting from a failure of embryonic migration or proliferation by primitive melanoblasts. Although the nature of the molecular defect has been unclear, mice with a "dominant spotting" phenotype, which affects both skin and hair pigmentation in a pattern that is very similar to human piebaldism, have been shown to carry

Address correspondence and reprint requests to Roger A. Fleischman, M. D., Simmons Cancer Center, Department of Medicine, 5323 Harry Hines Boulevard, Dallas, TX 75235-8852.

Received for publication 25 October 1991 and in revised form 27 January 1992.

J. Clin. Invest.

(C) The American Society for Clinical Investigation, Inc.

0021-9738/92/06/1713/05 \$2.00

Volume 89, June 1992, 1713-1717 heterozygous mutations of the mouse c-kit gene $(2,3)$. Moreover, cytogenetic data have implicated the long arm of chromosome 4, a region which includes the human c-kit gene (4-6), in the pathogenesis of piebald trait in three children with large interstitial deletions and multiple congenital anomalies (7).

In accord with the hypothesis that mutations of the human gene can cause piebald trait, a mutation in c-kit that is linked to the piebald phenotype in one kindred has been reported recently (8). Although this amino acid substitution appears not to be a common polymorphism, a resultant alteration in receptor function has not been demonstrated. Similarly, we have recently described a cytogenetically normal piebald subject who carries a heterozygous deletion of the c-kit gene (9). However, because this deletion extends beyond c-kit, the involvement of a closely linked gene could not be excluded.

To detect additional cases of piebald kindreds with c-kit mutations, we have used genomic polymerase chain reaction $(\mathrm{PCR})^{1}$ to amplify individual exons of the c-kit gene. To simplify the analysis, we focused initially on five exons which encode most of the tyrosine kinase domain. Previous data from studies of mouse c-kit mutations suggested that a high proportion of point mutations occur in this region $(10,11)$. Before cloning and sequencing, the PCR products were screened for nucleotide alterations by single-stranded conformation polymorphism (SSCP) analysis, a technique that can detect a high frequency of single nucleotide changes in DNA sequences $<400$ bp in length (12).

Using this methodology, we demonstrate that one piebald subject manifests a variant SSCP pattern for the first exon encoding the tyrosine kinase domain of c-kit. Cloning and sequencing of this DNA segment reveals a mutation that substitutes a lysine for a glutamic acid at position 583. Because the identical mutation has been shown to completely abolish receptor kinase activity in the entirely homologous ATP-binding domain of the mouse c-kit gene $(10,11)$, these data strongly suggest that this mutation is the cause of piebaldism in this individual and that the c-kit receptor has a similar function in both human and mouse development.

\section{Methods}

Subjects. Seven piebald individuals (subjects A-G), each from unrelated kindreds, have been previously described (9). One subject (B) has been shown to carry a germ-line heterozygous deletion of the c-kit gene, while Southern blots of the c-kit gene from the other six cases were normal. Three additional subjects with suggestive but not diagnostic features of piebald trait are included in the current study. Subject $\mathrm{H}$ is a Hispanic infant born with a very small white forelock, but no family history or leukoderma. Subject I is a black female with no leukoderma, a history of a white forelock for the first several years of life, and a

1. Abbreviations used in this paper: PCR, polymerase chain reaction; SSCP, single-stranded conformation polymorphism. 
similarly affected brother. The white forelock is now indistinguishable at eight years of age. Subject $\mathbf{J}$ is a mentally retarded white male with the fragile $X$ syndrome who has been previously described $(13,14)$. Although this individual and his father both have a prominent white forelock and leukoderma, the pattern of depigmentation includes the upper thoracic paravertebral areas, an atypical area for piebaldism (1). None of the subjects has extracutaneous manifestations that would suggest the diagnosis of Waardenburgs syndrome, which also has pigmentary disturbances and maps to human chromosome 2 (15).

Oligonucleotide primers. In the absence of sequence data for the introns of human c-kit, the primer oligonucleotides were located within the exons at intron boundaries predicted by homology with the human c-fms gene (16). To amplify the exons encoding the tyrosine kinase domains of c-kit, primers complementary to the human c-kit sequences (4) homologous to c-fms exon 12 (c-kit nucleotides 1669 1688, sense strand; nucleotides 1794-1775, antisense strand), 13 (1796-1815, sense; 1899-1880, antisense), 14 (1901-1919, sense; 2011-1993, antisense), 18 (2383-2401, sense; 2505-2487, antisense), and 19 (2506-2525, sense; 2617-2598, antisense) were synthesized. Although this method will not detect mutations occurring within the coding sequence complementary to the primers, $\sim 70 \%$ of the c-kit coding sequence is predicted to lie between the primers.

SSCP. For the detection of single-stranded conformation polymorphisms, PCR reactions were performed with $1 \mu \mathrm{g}$ genomic DNA, 50 $\mu \mathrm{M}$ each dNTP, $0.4 \mu \mathrm{M}$ each oligonucleotide primer, $10 \mathrm{mM}$ Tris- $\mathrm{HCl}$ $(\mathrm{pH}=8.3$ ), $50 \mathrm{mM} \mathrm{KCl}, 1.5 \mathrm{mM} \mathrm{MgCl}, 0.25 \mathrm{U}$ Thermus aquaticus DNA polymerase (Perkin-Elmer Cetus, Norwalk, CT), and $10 \mu \mathrm{Ci}$ of [ $\left.\alpha^{-}{ }^{32} \mathrm{P}\right] \mathrm{dCTP}(3,000 \mathrm{Ci} / \mathrm{mmol}, 10 \mathrm{mCi} / \mathrm{ml})$ in a final vol of $25 \mu \mathrm{l}$. PCR was performed for 40 cycles at a denaturation temperature of $94^{\circ}$ for 1 min, primer annealing at $55^{\circ}$ for $1 \mathrm{~min}$, and extension at $72^{\circ}$ for $2 \mathrm{~min}$. The PCR product $(1.5 \mu \mathrm{l})$ was added to $20 \mu \mathrm{l}$ of formamide dye $(98 \%$ formamide- $20 \mathrm{mM}$ EDTA- $0.05 \%$ bromophenol blue) and immediately before electrophoresis, the samples were heated in a boiling water bath for $6 \mathrm{~min}$. Aliquots $(2 \mu \mathrm{l})$ of each denatured sample were loaded onto a $38 \mathrm{~cm} \times 20 \mathrm{~cm} \times 0.4 \mathrm{~mm} 5.5 \%$ polyacrylamide gel (19:1 ratio of acrylamide to bis-acrylamide) with $10 \%$ glycerol and $2 \times$ TBE buffer ( $50 \mathrm{mM}$ Tris ( $\mathrm{pH}=8.0$ )- $50 \mathrm{mM}$ boric acid-1 mM EDTA). Electrophoresis was performed at $300 \mathrm{~V}$ at room temperature for 16-24 h. After electrophoresis, gels were transferred to $3 \mathrm{M}$ paper (Whatman Inc., Clifton, $\mathrm{NJ}$ ) and dried on a vacuum slab gel dryer for $2 \mathrm{~h}$ at $80^{\circ}$. Autoradiography with Kodak X-Omat film at room temperature without intensifying screens allowed detection of PCR products in 4-12 h of exposure.

DNA cloning and sequencing. PCR was carried out as described above with the modification that the total vol was $100 \mu$ and the concentration of dNTPs was $200 \mu \mathrm{M}$ with no radioactive label added. To confirm the absence of contamination in negative control samples and to ensure that the PCR product was a single band of the appropriate size, $1 \mu \mathrm{l}$ of the PCR product was visualized after electrophoresis in a $3 \%$ NuSieve (FMC Bioproducts, Rockland, ME)-1\% agarose minigel. To prepare the DNA for ligation, $1 \mu 1$ of T4 DNA polymerase was added to the PCR reaction mixtures and incubated an additional 20 $\min$ at $37^{\circ}$. The reaction product was then purified by electrophoresis overnight at $300 \mathrm{~V}$ on $10 \%$ polyacrylamide gels, visualized by ethidium bromide staining, excised, and cloned into M13mp18 by blunt end ligation with T4 DNA ligase (17). M13 single-stranded DNA was sequenced with modified T7 DNA polymerase (Sequenase, Version 2.0; United States Biochemical Corp., Cleveland, OH) using $\left[\alpha{ }^{35}\right.$ S $]$ dATP $(1,000 \mathrm{Ci} / \mathrm{mmol})$ according to the protocol supplied by the manufacturer.

\section{Results}

Amplification of c-kit exons. Southern blot analyses failed to detect rearrangements of c-kit gene in the seven subjects previously described (9) or in the three additional subjects reported here (data not shown). One explanation for this result is that piebaldism frequently results from point mutations or small deletions/insertions that cannot be detected by Southern analysis. To identify such changes, genomic PCR was used to amplify five exons predicted to encode most of the tyrosine kinase domains of c-kit. The sequences and locations of the oligonucleotide primers for these exons were derived by aligning the cDNA sequence of c-kit with the known intron-exon boundaries of human c-fms (16). The sizes of the products amplified with these primers exactly parallels the published data for the homologous exons of human c-fms (data not shown).

$S S C P$. To screen exons from the 10 subjects for mutations, the amplified DNA fragments were subjected to SSCP analysis. The patterns for DNA fragments homologous to c-fms exons 13-14 and 18-19 were identical in all 10 subjects (data not shown). However, for the fragment homologous to c-fms exon 12, one subject demonstrates a variant SSCP pattern (Fig. 1, lane 3). The major band at the top of the gel in all of the lanes corresponds to the renatured double-stranded PCR product. The two faster migrating bands are thought to represent the two single-stranded chains of the denatured PCR product. As shown in lane 3, two additional bands are present in this subject's DNA, suggesting the presence of an altered DNA sequence in one of the two alleles of this c-kit sequence.

DNA sequencing. To determine the basis for the variant SSCP in this subject (lane 3), the PCR product was cloned into M13 by blunt end ligation (see Methods). Sequencing of these clones demonstrated that this subject carries a heterozygous transition in codon 583 (GAG $\rightarrow$ AAG), which results in the substitution of the basic amino acid lysine for the acidic amino acid glutamic acid (Fig. 2). This mutation occurs in a residue that is conserved in many tyrosine kinases $(10,11)$ and lies near the ATP-binding pocket of the c-kit kinase domain (18). Both the normal and mutated alleles were detected in two independent PCR reactions. Of eight clones sequenced, the mutation was found in five clones and the normal sequence in three. With the exception of the point mutation at codon 583, the DNA sequence determined from these clones was identical to the published sequence for the human c-kit cDNA (4). In addition, although the amino acid sequence of this exon is identical in both mouse and human c-kit, species-specific differences in the nucleotide sequence confirmed the human origin of these clones (6).

Homology of the human phenotype to the $W^{37}$ mutant mouse. The mutation identified in this piebald subject produces the same amino acid change as the previously described

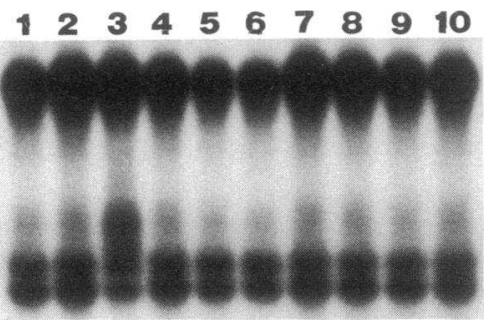

Figure 1. SSCP of c-kit exon 12 amplified from the DNA of 10 piebald subjects. DNAs were amplified by PCR, denatured, and subjected to polyacrylamide gel electrophoresis under neutral conditions. No variants were detected in lanes 1 and 2 and

4-10. Lane 3 shows a variant pattern with two additional bands. The major band in all samples corresponds to the native double-stranded PCR product. The samples analyzed in lanes $1-9$ are from subjects $A$, C, D, E, F, G, H, I, and J, respectively (see Methods). The lane 10 sample is from subject $\mathrm{B}$, who has a heterozygous deletion of c-kit (9). 

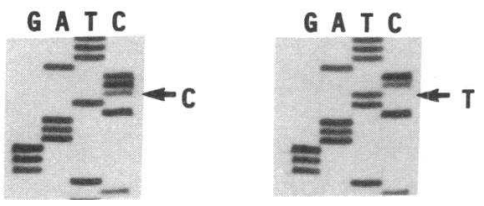

Lys Trp lys Phe Pro

Mutant

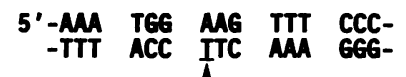

Noranal

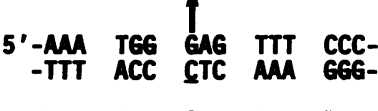

lys Trp Glu Phe Pro

Figure 2. Partial nucleotide sequence analysis of c-kit cDNA from the piebald subject with an SSCP variant. The presumptive exon 12 from subject D (Fig. 1, lane 3) was amplified by PCR and cloned into M13 by blunt end ligation. The nucleotide sequences were determined for eight clones obtained from two independent PCR reactions. Shown are portions of the sequencing ladder spanning the mutation at nucleotide 1768 for one normal allele and one mutant allele. The normal allele had the same sequence as published for human c-kit (4), and was confirmed in two other clones. The mutant allele had the same sequence as described except at codon 583, which was AAG instead of GAG, resulting in the substitution of lysine for glutamic acid. The sequence of this clone was confirmed in four other clones from two independent PCR reactions.

$W^{37}$ mutation in the mouse c-kit gene $(10,11,19)$. To compare the phenotype produced by the same mutation in two different species, mice heterozygous for the $W^{37}$ mutation were obtained from The Jackson Laboratory (Bar Harbor, ME). The heterozygous subject and her almost identically affected son manifest a large white hair forelock and depigmentation which extends from the vertex of the head to the root of the nose and involves the medial eyebrows and chin. Depigmentation is also extensive on the extremities, ventral abdomen and thorax, and extends to involve both sides of the back. In a similar fashion, the heterozygous mouse, which is normally entirely black, exhibits very extensive hypopigmentation, previously estimated at $\sim 85 \%$ of the coat $(20)$. The residual pigmentation in the mouse is limited largely to the face, ears, rump, and a few areas on the dorsal surface of the back. One difference between the two species, however, is the more diffuse and apparently random pattern of dorsal pigmentation seen in the mouse homologue, in contrast to the nearly complete sparing of the central back in the human kindred, an almost invariant feature of human piebald trait (1).

\section{Discussion}

In this paper we report the detection of a point mutation in the c-kit membrane receptor gene that is associated with the human developmental defect piebald trait. This mutation is nonconservative, resulting in the substitution of a lysine for a glutamic acid in the tyrosine kinase domain of the c-kit gene. Moreover, the mutation is identical to a previously characterized mutation in the mouse c-kit gene which results in a loss of autophosphorylation activity in the protein product in vitro $(10,11)$ and a "dominant negative" phenotype with extensive depigmentation in vivo (20). Because the amino acid sequence of this region is completely conserved between mouse and man $(4,6)$, the human mutation is sufficient to account for the dominant negative phenotype observed clinically and is almost certainly the cause of the piebaldism in this case.
The amino acid residue $\mathrm{Glu}^{583}$, which is replaced by lysine in one allele of the c-kit gene in this piebald subject, forms part of a consensus sequence Trp-Glu-X-X-Arg, which is found in all members of the platelet-derived growth factor receptor and insulin receptor subfamilies, and in some members of the c-src and c- $a b l$ subfamilies of transmembrane receptor tyrosine kinases $(10,11)$. The loss of autophosphorylation activity associated with this mutation of the mouse c-kit gene presumably results from its location just amino terminal to the ATP-binding consensus sequence, Gly-X-Gly-X-X-Gly, which is found in all protein kinases and is known to be critical for kinase activity (18). In addition to a loss of autophosphorylation activity, the mature $W^{37}$ kit protein appears to be less stable than the wild-type protein product and incapable of association with signaling proteins phospholipase $\mathrm{C}_{\gamma} 1$ and phosphatidylinositol-3'kinase $(10,11,19)$. Thus, it seems likely that the homologous human mutation would also interfere with the signal transduction pathway triggered by interaction of the receptor with its ligand. Recently, a mutation in the same consensus sequence, substituting a glutamine for the conserved arginine residue, has been reported to result in decreased activity of the human insulin receptor, a result consistent with a positive function for this domain (21).

Although the mutation described here results in an unusually extensive pattern of depigmentation, the deletion of one c-kit allele appears to be associated with a more limited defect of pigmentation (9). Similarly, the homologous mouse $W^{37}$ mutation produces more depigmentation in heterozygotes $(20)$ than the deletion of a single mouse c-kit allele (22). To explain the increased effects of this and other dominant negative mutant c-kit receptors (23), it has been suggested that the transduction of extracellular signals requires oligomerization of receptor molecules in the presence of ligand (24). Thus, the point mutation described here could cause a dominant negative effect by producing defective or unstable heterodimers with impaired kinase activity, or by binding ligand nonproductively in situations where ligand is limiting. In contrast, mutations which result in loss of expression of a normal protein product would be expected to cause a 50\% reduction in receptor number and a relatively limited pigmentation defect. Mutations in other transmembrane receptor tyrosine kinases, such as the epidermal growth factor and insulin receptors (25-27), as well as in the thyroid nuclear receptor (28), have also been associated with dominant negative mechanisms.

An interesting question is why mutations of the c-kit gene leave some areas pigmented and other areas totally unpigmented. One possibility is that the alteration in receptor function impairs migration (29), proliferation (30), or survival (31) of the neural crest-derived pigment stem cells, resulting in a failure of melanoblast colonization at anatomic sites most distant from the neural crest. Alternatively, melanoblasts migrating into the forehead and other frequently involved areas may be at the low end of a gradient for the c-kit receptor ligand (32, 33). Recent evidence suggests that after the migration of neural crest-derived cells, a second phase of receptor-dependent melanocyte proliferation occurs at $14.5 \mathrm{~d}$ of mouse gestation in the mesoderm of embryonic skin (34). The existence of two distinct stages of c-kit receptor dependence would be consistent with a model in which "null" mutations affect primarily the first phase of primitive neural crest-derived cell migration, resulting in a limited pigmentation defect at specific sites, while 
dominant negative mutations also affect the second phase of melanocyte proliferation, accounting for the more diffuse, almost random pattern of depigmentation seen in these mutant mice. If this model is correct, the more complete preservation of dorsal pigmentation in human piebaldism suggests that melanocyte proliferation occurring within the mesoderm may be less critical or differently regulated in human as opposed to mouse development.

In addition to their effects on pigmentation, dominant negative mutations generally cause a mild macrocytic anemia and hypogonadism in heterozygous mice (20). In the most extreme case, two abnormal c-kit alleles invariably cause both severe anemia and sterility in homozygous mice (35). Thus, the function of this tyrosine kinase membrane receptor is necessary not only for pigment cell development but also, in the mouse, for hematopoietic stem cells and germ cells as well. While the current studies show a close correspondence between receptor function in the melanocyte development of both species, an essential role for human c-kit in human hematopoiesis and germ cell development has not been demonstrated, although the gene is expressed in human germ cell tumors (36), and hematopoietic cells $(37,38)$. In this regard it is interesting to note that subject $D$ was not anemic (data not shown) and appears to have normal fertility. However, in contrast to other dominant negative mutations of c-kit, the $W^{37}$ mutation is unusual in its lack of effect on the hematopoietic or germ cell lineages in heterozygous mice (20). On the other hand, mild anemia in a single individual may be difficult to distinguish from the broad range of "normal" values established for an outbred population. Studies to assess the proliferative response of piebald bone marrow cells, for example by exposure to the ligand for the c-kit receptor, may unmask defects that are not evident under homeostatic conditions.

Since c-kit receptor function and signaling presumably also depend on interaction with an appropriate ligand, one might expect mutant forms of the ligand for this receptor to produce a similar defect in melanocyte development. In fact, mutations in the mouse Steel gene, which encodes the ligand for c-kit (39-42), cause a similar spotting phenotype in heterozygous mice (35). Thus, some cases of piebald trait may prove to result from mutations in this gene, rather than in the receptor gene. Using an approach similar to that described here, we are currently screening exons of the c-kit ligand gene for mutations in other piebald subjects.

The present studies strongly suggest that the c-kit mutation described here is the cause of piebald trait in one subject. Taken together with the previously reported cases involving a point mutation (8) and a deletion (9) of c-kit, the data argue strongly that mutations in the human c-kit gene cause human piebald trait. Moreover, additional examples of mutations in c-kit or its ligand are likely to be demonstrated by more exhaustive sequencing studies of these genes in other piebald subjects since only a small proportion of the c-kit open reading frame has been examined in these initial studies. Interestingly, compared to the relatively limited number of c-kit mutants that are known in the mouse, the number of spontaneous mutations available in piebald individuals is potentially very large, with an estimated population frequency of 1 in 40,000 (1). The molecular characterization of these additional mutations in piebald kindreds should facilitate the definition of structural elements necessary for signal transduction by transmembrane protein tyrosine kinases and provide further insight into the role of c-kit in human embryogenesis and differentiation.

\section{Acknowledgments}

We thank Golder Wilson and Lew Waber for referral of piebald individuals; Richard Baer, Michael Brown, Jonathan Cohen, Helen Hobbs, Graham Smith, and John Minna for their interest and helpful discussions. Cary Yang-Chuan Yang and Fred Scott provided excellent technical assistance.

This work was supported by the Nasher Family Cancer Research Program, American Cancer Society Grant IN-142, and the Harold C. Simmons Cancer Center.

Note added in proof. Since this manuscript was accepted for publication, three additional piebald kindreds with point mutations in c-kit have been reported (43). Photographs of the human kindred and mouse homologue described in this manuscript have recently been published (44).

\section{References}

1. Ortonne, J.-P. 1988. Piebaldism, Waardenburg's syndrome, and related disorders. Dermatol. Clin 6:205-216.

2. Chabot, B., D. A. Stephenson, V. M. Chapman, P. Besmer, and A. Bernstein. 1988. The proto-oncogene c-kit encoding a transmembrane tyrosine kinase receptor maps to the mouse $W$ locus. Nature (Lond.). 335:88-89.

3. Geissler, E. N., M. A. Ryan, and D. E. Housman. 1988. The dominantwhite spotting $(W)$ locus of the mouse encodes the c-kit proto-oncogene. Cell. 55:185-192.

4. Yarden, Y., W.-J. Kuang, T. Yang-Feng, L. Coussens, S. Munemitsu, T. J. Dull, E. Chen, J. Schlessinger, U. Francke, and A. Ullrich. 1987. Human protooncogene c-kit: a new cell surface receptor tyrosine kinase for an unidentified ligand. EMBO (Eur. Mol. Biol. Organ.) J. 6:3341-3351.

5. d'Auriol, L., M.-G. Mattei, C. André, and F. Galibert. 1988. Localization of the human c-kit protooncogene on the q11-q12 region of chromosome 4. Hum. Genet. 78:374-376.

6. Qui, F., P. Ray, K. Brown, P. E. Barker, S. Jhanwar, F. H. Ruddle, and P. Besmer. 1988. Primary structure of c-kit: relationship with the CSF-1/PDGF receptor kinase family-oncogenic activation of v-kit involves deletion of extracellular domain and C terminus. EMBO (Eur. Mol. Biol. Organ.) J. 7:1003-1011.

7. Hoo, J. J., R. H. A. Haslam, and C. van Orman. 1986. Tentative assignment of piebald trait gene to chromosome band 4q12. Hum. Genet. 73:230-231.

8. Giebel, L. B., and R. A. Spritz. 1991. Mutation of the $K I T$ (mast/stem cel growth factor receptor) protooncogene in human piebaldism. Proc. Natl. Acad. Sci. USA. 88:8696-8699.

9. Fleischman, R. A., D. L. Saltman, V. Stastny, and S. Zneimer. 1991. Deletion of the c-kit protooncogene in the human developmental defect piebald trait. Proc. Natl. Acad. Sci. USA. 88:10885-10889.

10. Nocka, K., J. C. Tan, E. Chiu, T. Y. Chu, P. Ray, P. Traktman, and P. Besmer. 1990. Molecular basis of dominant negative and loss of function mutations at the murine c-kit/white spotting locus: $W^{37}, W^{2}, W^{41}$, and $W . E M B O$ (Eur. Mol. Biol. Organ.) J. 9:1805-1813.

11. Reith, A. D., R. Rottapel, E. Giddens, C. Brady, L. Forrester, and A. Bernstein. 1990. $W$ mutant mice with mild or severe developmental defects contain distinct point mutations in the kinase domain of the c-kit receptor. Genes \& Dev. 4:390-400.

12. Orita, M., Y. Suzuki, T. Sekiya, and K. Hayashi. 1989. Rapid and sensitive detection of point mutations and DNA polymorphisms using the polymerase chain reaction. Genomics. 5:874-879.

13. Telfer, M. A., M. Sugar, E. A. Jaeger, and J. Mulcahy. 1971. Dominant piebald trait (white forelock and leukoderma) with neurological impairment. Am. J. Med. Genet. 23:383-389.

14. Finucane, B., C. I. Scott, Jr., and M. B. Kurtz. 1991. Concurrence of dominant piebald trait and fragile X syndrome. Am. J. Hum. Genet. 48:815.

15. Foy, C., V. Newton, D. Wellesley, R. Harris, and A. P. Read. 1990. Assignment of the locus for Waardenburg syndrome type I to human chromosome $2 \mathrm{q} 37$ and possible homology to the splotch mouse. Am. J. Hum. Genet. 46:1017-1023.

16. Hampe, A., B.-M. Shamoon, M. Gobet, C. J. Sherr, and F. Galibert. 1989. Nucleotide sequence and structural organization of the human FMS proto-oncogene. Oncogene Res. 4:9-17.

17. Sambrook, J., E. F. Fritsch, and T. Maniatis. 1989. Molecular Cloning: A 
Laboratory Manual. Second ed. Cold Spring Harbor Laboratory, Cold Spring Harbor, NY.

18. Hanks, S. K., A. M. Quinn, and T. Hunter. 1988. The protein kinase family: conserved features and deduced phylogeny of the catalytic domains. Science (Wash. DC). 241:42-52.

19. Reith, A. D., C. Ellis, S. D. Lyman, D. M. Anderson, D. E. Williams, A Bernstein, and T. Pawson. 1991. Signal transduction by normal isoforms and $W$ mutant variants of the Kit receptor tyrosine kinase. EMBO (Eur. Mol. Biol. Organ.) J. 10:2451-2459.

20. Geissler, E. N., E. C. McFarland, and E. S. Russell. 1981. Analysis of pleiotropism at the dominant white-spotting $(W)$ locus of the house mouse: a description of ten new $W$ alleles. Genetics. 97:337-361.

21. Kusari, J., Y. Takata, E. Hatada, G. Freidenberg, O. Kolterman, and J. M. Olefsky. 1991. Insulin resistance and diabetes due to different mutations in the tyrosine kinase domain of both insulin receptor gene alleles. J. Biol. Chem. 266:5260-5267.

22. Lyon, M. F., P. H. Glenister, J. F. Loutit, E. P. Evans, and J. Peters. 1984. A presumed deletion covering the $W$ and $P h$ loci of the mouse. Genet. Res. 44:161-168.

23. Tan, J. C., K. Nocka, P. Ray, P. Traktman, and P. Besmer. 1990. The dominant $W^{42}$ spotting phenotype results from a missense mutation in the c-kit receptor kinase. Science (Wash. DC). 247:209-212.

24. Herskowitz, I. 1987. Functional inactivation of genes by dominant negative mutations. Nature (Lond.). 329:219-222.

25. Basu, A., M. Raghunath, S. Bishayee, and M. Das. 1989. Inhibition of tyrosine kinase activity of the epidermal growth factor (EGF) receptor by a truncated receptor form that binds to EGF: role for interreceptor interaction in kinase regulation. Mol. Cell. Biol. 9:671-677.

26. Kashles, O., Y. Yarden, R. Fischer, A. Ullich, and J. Schlessinger. 1991 A dominant negative mutation suppresses the function of normal epiderma growth factor receptors by heterodimerization. Mol. Cell. Biol. 11:1454-1463.

27. Chou, O. K., T. J. Dull, D. S. Russell, R. Gherzi, D. Lebwohl, A. Ullrich, and D. Rosen. 1987. Human insulin receptors mutated at the ATP binding site lack protein tyrosine kinase activity and fail to mediate post receptor effects of insulin. J. Biol. Chem. 262:1842-1847.

28. Krishna, V., K. Chatterjee, T. Nagaya, L. D. Madison, S. Datta, A. Rentoumis, and J. L. Jameson. 1991. Thyroid hormone resistance syndrome. Inhibition of normal receptor function by mutant thyroid hormone receptors. J. Clin. Invest. 87:1977-1984.

29. Schaible, R. H. 1969. Clonal distribution of melanocytes in piebald-spotted and variegated mice. J. Exp. Zool. 172:181-199.

30. Mayer, T. C. 1979. Interactions between normal and pigment cell populations mutant at the dominant-spotting $(W)$ and steel $(S l)$ loci in the mouse. $J$ Exp. Zool. 210:81-88.
31. Mintz, B. 1974. Gene control of mammalian differentiation. Annu. Rev. Genet. 8:411-470.

32. Matsui, Y., K. M. Zsebo, and B. L. M. Hogan. 1990. Embryonic expression of a haematopoietic growth factor encoded by the $S /$ locus and the ligand for c-kit. Nature (Lond.). 347:667-669.

33. Keshet, E., S. D. Lyman, D. E. Williams, D. M. Anderson, N. A. Jenkins, N. G. Copeland, and L. F. Parada. 1991. Embryonic RNA expression patterns of the c-kit receptor and its cognate ligand suggest multiple functional roles in mouse development. EMBO (Eur. Mol. Biol. Organ.) J. 10:2425-2435.

34. Nishikawa, S., M. Kusakabe, K. Yoshinaga, M. Ogawa, S.-I. Hayashi, T. Kunisada, T. Era, T. Sakakura, and S.-I. Nishikawa. 1991. In utero manipulation of coat color formation by a monoclonal anti-c-kit antibody: two distinct waves of c-kit dependency during melanocyte development. EMBO (Eur. Mol. Biol. Organ.) J. 10:2111-2118

35. Russell, E. S. 1979. Hereditary anemias of the mouse: a review for geneticists. Adv. Genet. 20:357-459.

36. Strohmeyer, T., S. Peter, M. Hartmann, S. Munemitsu, R. Ackermann, A Ullich, and D. J. Slamon. 1991. Expression of the hst-1 and c-kit protooncogenes in human testicular germ cell tumors. Cancer Res. 51:1811-1816.

37. André, C., L. d'Auriol, C. Lacombe, S. Gisselbrecht, and F. Galibert. 1989. c-kit mRNA expression in human and murine hematopoietic cell lines. Oncogene. 4:1047-1049.

38. Wang, C., J. E. Curtis, E. Geissler, E. A. McCulloch, and M. D. Minden. 1989. The expression of the proto-oncogene c-kit in the blast cells of acute myeloblastic leukemia. Leukemia (Basingstoke). 3:699-702.

39. Copeland, N. G., D. J. Gilbert, B. C. Cho, P. J. Donovan, N. A. Jenkins, D. Cosman, D. Anderson, S. D. Lyman, and D. E. Williams. 1990. Mast cel growth factor maps near the Steel locus on mouse chromosome 10 and is deleted in a number of Steel alleles. Cell. 63:175-183.

40. Flanagan, J. G., and P. Leder. 1990. The kit ligand: a cell surface molecule altered in Steel mutant fibroblasts. Cell. 63:185-194.

41. Zsebo, K. M., D. A. Williams, E. N. Geissler, V. C. Broudy, F. H. Martin, H. L. Atkins, R.-Y. Hsu, N. C. Birkett, K. H. Okino, D. C. Murdock, et al. 1990 Stem cell factor is encoded by the $S /$ locus of the mouse and is the ligand for the c-kit tyrosine kinase receptor. Cell. 63:213-224.

42. Huang, E, K Nocka, D. R. Beier, T-Y Chu, J. Buck, H-W. Lahm, D. Wellner, P. Leder, and P. Besmer. 1990. The hematopoietic growth factor KL is encoded by the $S /$ locus and is the ligand of the c-kit receptor, the gene product of the $W$ locus. Cell. 63:225-233.

43. Spritz, R. A., L. B. Giebel, and S. A. Holmes. 1992. Dominant negative and loss of function mutations of the c-KIT (mast/stem cell growth factor receptor) proto-oncogene in human piebaldism. Am. J. Hum. Genet. 50:261-269.

44. Biology in Pictures. 1992. Genetic diseases: of mouse and child. Curr. Biol. 2:161. 